\section{FERTILISATION OF FLOWERS BY INSECTS $\mathrm{XVI}$.}

Alpine Species of Gentiana adapted to Lepidoptera. GENTIANA BAVARICA (Fig. 106-108), G. verna

(Fig. IO9-IrI), G. nivalis (Fig. II2-I 14), of which I have examined living specimens in the Alps, and G. imbricata, astiva, pumila, and utriculosa, of which I have examined only dried specimens, ${ }^{2}$ agree so completely in the structure of their flowers, and in their contrivances for cross-fertilisation by insects, that they all obviously belong to the same section of the genus Gentiana, and are adapted to the same group of visiting insects. They all possess a long narrow corolla (Fig. IO6), ${ }^{3}$ which contains in its lowermost portion the honey, secreted, as in our

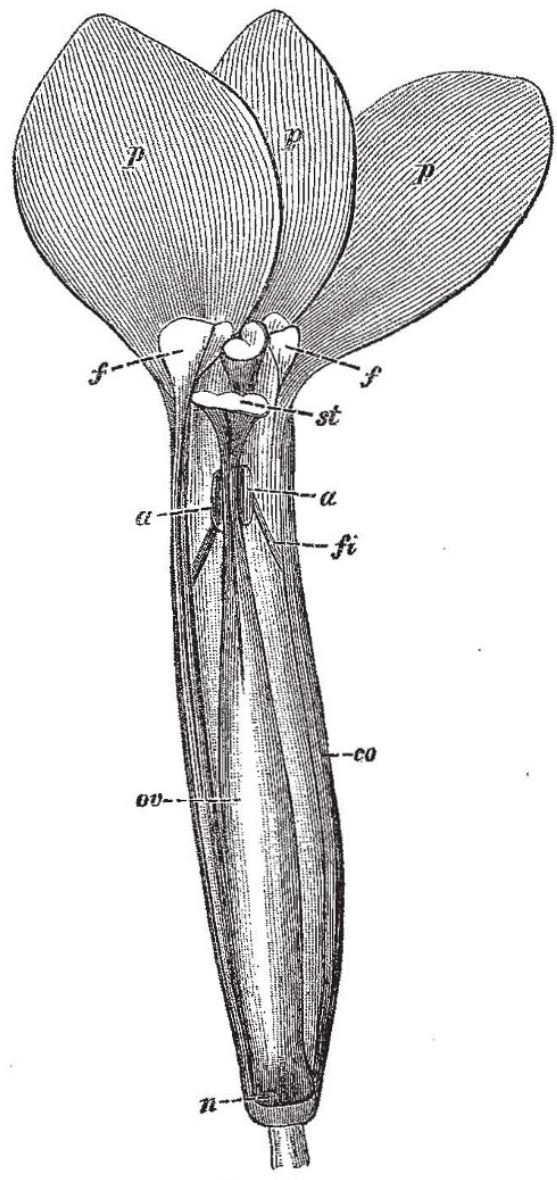

FIg. 106.

Fras 106-ro8.-Gentiana bavarica. FIG. ro6.-Lateral view of a flower which begins twisting and closing, the calyx and the anterior portion of the corolla having been removed $\left(3 \frac{1}{2}: x\right)$. FIG. xo7. - The same flower viewed from above $\left(3 \frac{1}{4}: x\right)$. The margin of the circular stigma is already covered by the revolving corolla. Fig. x08. - The stigma seen from above $(7: x) \cdot 4$

two first groups, by an annular swelling at the base of the pistil 5 ( $n$, Fig. 106, III, I13). They all have the entrance to the corolla-tube closed by the bi-lobed stigma being

Continued from p. 3 rg.

For specimens of G, pumila, astiva, prostrata, Froelichii, and pur${ }^{2}$ For specimens of to. prof Ascherson of Berlio.

purea, I am indebted to Prof. Ascherson of Berlia. the other species.

the other species. The filaments, $n=$ nectary, $0=$ openings con$a=$ anthers, $c=$ sepals, $s t=$ stigma, $f=$ ducting to the honey, ov ovary, $p=$ petals, $s$ possible.

folds of the corlla $5 \mathrm{I}$ found the length of the corolla-tube, from $26.28 \mathrm{~mm}$; $G$. verna and var. the species in question as follows: G. brachyphylla, 23 ; G. bavarica, $20-22 ; G$, utric dilated into a circular disc (st. Fig. 1c6, 109, 112), and bordered at its margins with hair-like papillæ (Fig. I08). In all of them small openings are visible in the fullyopened flower between the margin of the stigma and the inclosing corolla (Fig. IO9); but as soon as the corolla begins twisting (Fig. 1 ro), these openings are concealed. In all of them the anthers surround the stigma, thus placing their pollen on the way to the honey (a, Fig. 106, I I0, I14). They can all, therefore, be fertilised only by such insects as have a proboscis sufficiently long to reach the base of the corolla, and at the same time either sufficiently slender to enter through the small openings (Lepidoptera), or sufficiently strong forcibly to enlarge the entrance of the flower (humble-bees). Such an enlargement, indeed, would be possible by the expansion of the same folds between the petals ( $f$. Fig. 106, 107, xog, IIo, II2), by which the flower is enabled to twist, and to close, as soon as colder weather frightens away its natural fertilisers.

Now, looking about to discover what Lepidoptera and humble-bees might be the natural tertilisers of the present

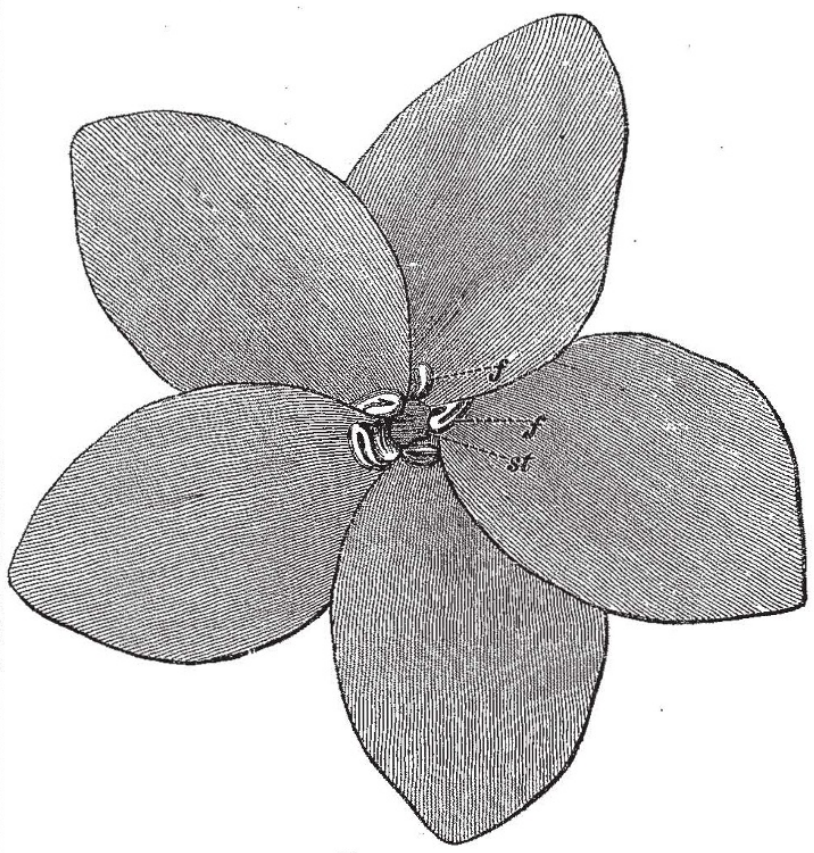

FIG. Io7

group, I was surprised at the fact that of all the $I 62$ species of Lepidoptera which I had observed visiting flowers in the Alps, Macroglossa stellatarum alone has a proboscis sufficiently long $(25-28 \mathrm{~mm}$.) to reach the honey in all the species of Gentiana in question, and that of the Alpine humble-bees, even those provided with the longest proboscis of all, Bombus hortorum (18-21 mm.) and B. opulentus, Gerst. (22 $\mathrm{mm}$.), are incapable of reaching the honey in all the above-named species, except by thrusting the whole of their head into the narrow corolla-tube. Moreover, direct observation seems to prove that humble-bees insert at the most their proboscis into these

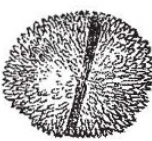

FIG. x08: flowers, but never their whole head. For instance, in the Albula Pass, July 28 , 1876, I saw a humble-bee flying about for a long time in search of flowers; at length it hastily visited Gentiana verna, but having only once thrust its proboscis in:o a flower, it flew away out of my sight. Likewise near Pontresina, August 4, 1876, I saw Gentiana nivalis visited by Bombus mendax, Gerst. \&, but, after having hastily tried one or two flowers in the same 
manner, it passed over to Trifolium nivale, which it then sucked perseveringly. If from these observations we may infer that the forcible enlargement of the narrow corollatube of the species of Gentiana in question is too inconvenient for the humble bees, then the only insects capable of gaining the honey in all the species of the present group and capable of regularly visiting and crossfertilising them, are Macroglossa stellatarum, and perhaps some other Sphingidæ not yet observed by myself in the

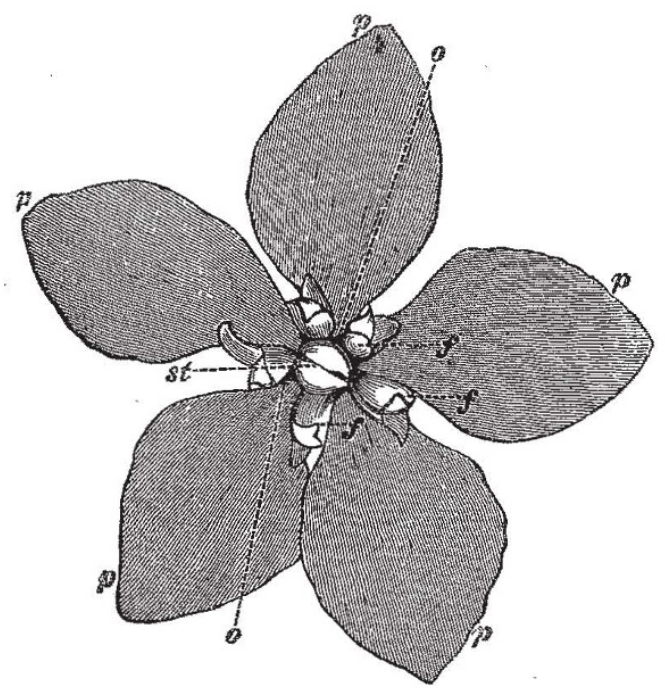

Fig. rog.

F1Gs. xog-rrx--Gentiana verna ( $\left.3 \frac{1}{2}: x\right)$. FIG. rog.-Flower, completely opened, seen from above. FiG. XTo.- Upper portion of the same fiower, bisected longitudinally, showing the pistil and the anthers. FfG. xx. - Lowermost portion of the same flower, showing the nectary.

Alps. The smallest of the species in question, $G$. nivalis (13-16 mm.), G. imbricata (1 $5 \mathrm{~mm}$.), and $G$. pumila (16-18 $\mathrm{mm}$.), may also be fertilised by some moths ${ }^{1}$ and by many butterflies $^{2}$ which will all easily insert their slender proboscis into one of the small openings at the base of the corolla-tube, then, withdrawing it smeared with pollen, will leave some pollen-grains on the margin of the stigmatic disc, and, when inserting the proboscis into another flower, will effect its cross-fertilisation by stripping off some of the pollen-grains from the hair-like papillæ at the margin of
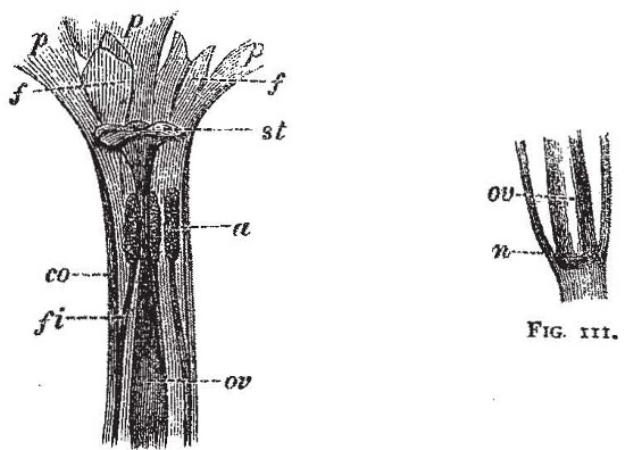

Fig. $x$ xo.

the stigmatic discs. Humble-bees, on the contrary, at all events, seem to be of very small or no importance as fertilisers of this group. If thus, by indirect inference, we are led to the conclusion that the present group

Plusia gamma, $15-16 \mathrm{~mm}$; P. interrogationis, 15 ; P. Hocheriwarti, 3..

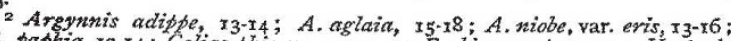
A. paphia, $\mathrm{x}_{2-\mathrm{x}_{4}}$; Colias phicomone, $\mathrm{x}_{3}-\mathrm{x}_{4}$; Erebia goante, $\mathrm{xr}^{-x_{4}}$; Hesperia sylwanus, 16 ; Papilio machaon, 18-20; Pararge maera, 13-14; Parnassius rapallo, 12-13; $P$. delius, x1-16; Pieris brassica, x5-16; P. cratagi, 15; $P$. is exclusively adapted to Lepidoptera, we ought to embrace this opinion with due precaution; for all visits of Lepidoptera, hitherto directly observed by the comparison of the length of their proboscis with the length of the corolla-tube, prove to have been only fruitless attempts. On $G$. nivalis (corolla-tube ${ }_{13-16}$ mm.), near Pontresina, August 4, 1876, I observed Canonympha satyrion, Esp. (proboscis, $7 \mathrm{~mm}$.), and Hesperia serratula, Rbr. (IO-II mm.) ; on G. verna (corolla-tube, $23 \mathrm{~mm}$.) in the Albula Pass, July 28, I876, I found Melitar aurinia, var. Merope, Prunn. (7 mm.), Argynnis pales, S. V. (9-10 $\mathrm{mm}$.), and Erebia lappona, Esp. (8-9 mm.); on $G$. bavarica (20-22 mm.), Kerner ${ }^{1}$ observed Agrotis cuprea (I2 mm.), I myself, upon the Piz Umbrail, July I5, 1875 , saw Erebia lappona, Esp. (8.9 mm.) ; in the Albula Pass, July $27,1876, E$. Lappona and Melitca asteria ( $5-6 \mathrm{~mm}$.); in the Val del Fain, August 5, 1876, Melitaa aurinia, var. Merope, Prunn. ( $7 \mathrm{~mm}$.), all easily inserting their proboscis into the corolla-tubes, but all apparently without any advantage to themselves, though, by their repeated fruitless attempts, some cross-fertilisation of the flowers may have been effected. No direct observation

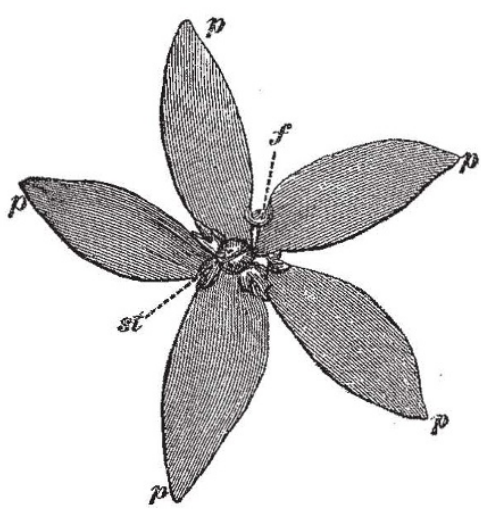

Frg. II2.
Frgs. Ir2-114-Gentiana nivalis $\left(3 \frac{1}{2}: \mathrm{x}\right)$. Fig $x 12,-$ Flower seen from above.

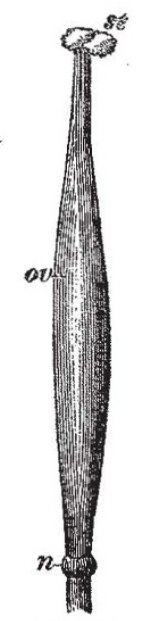

FIg. II2.
Figs. Ir2-II 4 -Gentiana nivalis $\left(3 \frac{1}{2}: x\right)$. Fig xr2,-Flower seen from above. FIG. II3.-Pistil. FIG. II4 - Upper portion of the fower bisected longiFIG. II3.-Phstil. FIG. II4 - Upper portion of the fower bisected longi-
tudinally, showing one of the anthers $\left(\alpha^{\prime}\right)$ in contact with the margins of the stigma.

of the true natural fertilisers of the species of Gentiana belonging to our fourth group has yet been made.

In former articles I have shown that frequently, of different species of the same genus, those possessing the most conspicuous flowers are adapted to cross-fertilisation by insects, whilst other species of the same genus, possessing less conspicuous flowers, have recourse to self-fertilisation, in case the visits of insects are wanting. This statement is also confirmed by the species of Gentiana in question. For in G. verna and bavarica, differing from nivalis not only by the considerably larger size of the separate flowers, but also by a number of flowers which stand close together, thus being easily seen from a great dis-

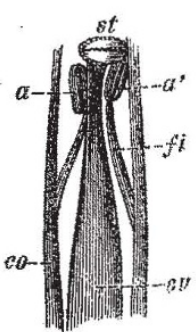

FIG. II4. tance, the possibility of self-fertilisation is excluded by the position of the stigma and the anthers (as shown by Fig. 106 and 110 ); whereas in Gentiana nivalis, whose flowers are much smaller and more distant one from another, one or some of the anthers commonly come into contact with the margin of the stigma (as shown by Fig. II4), and effect self-fertilisation in case cross-fertilisation by insects is wanting.

× Kerner, "Schutzmittel der Blüthen gegen unberufene Gäste." (Wien 1876); 
The most striking peculiarity of our fourth group of Gentiana is the sensibility of their flowers to the influence of the weather, which is apparently connected with the sensibility of their natural fertilisers to the same influence. The following observation clearly shows that different species differ widely in this sensibility, even when growing in the same locality. On the Piz Umbrail, July 16, I874, I had collected some plants of Gentiana bavarica, var, imbricata, and of G. verna, and put them in my sleeping-room in the Quarta Cantoniera, upon a plate filled with water. The next morning, at half-past four o'clock, I found the flowers of $G$. bavarica already opened, those of G. verna still closed. I placed the plate outside the window, where the intensity of light was at least as great, but the temperature much lower, and all the opened flowers began twisting. After they had closed, I brought them back into the room, and they opened again. Repeating this trial from half-past four to half-past six o'clock, I saw them two or three times closing and opening again. Gentiana verna, standing upon the same plate, during this time, had not yet opened a single flower.

From this observation, the further prosecution of which was prevented by my departure, it is obvious (I) that the opening of the flowers of these species of Gentiana is caused

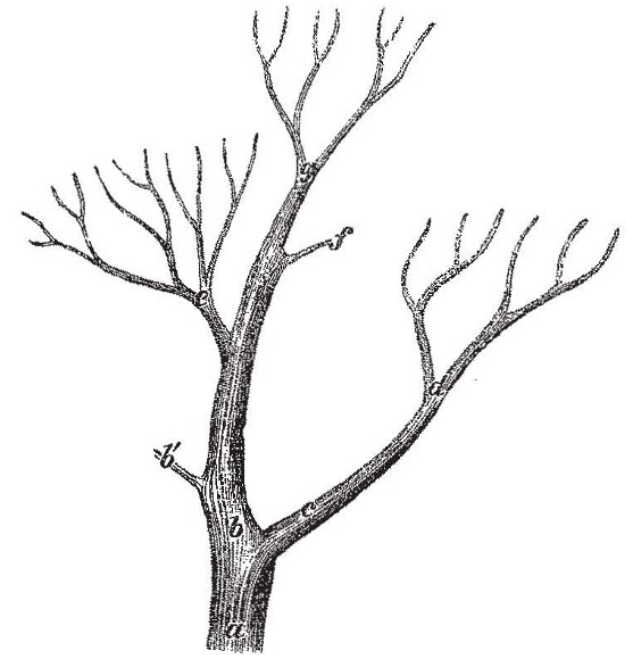

FrG. $\times 15$-Pedigree ot the species of Gentiana of Germany and Switzerland.

by heat, not by light; (2) that $G$. verna requires a higher temperature for opening than $G$. bavarica, var. imbricata. Possibly this is one of the causes which makes $G$. verna descend into sub-Alpine and low lands, whilst $G$. bavarica is confined to the Alpine region.

Comparing the present group with the foregoing ones, we need hardly doubt that it is most nearly allied to our second group, from which it differs only by the narrowness of the corolla, by the further development of the folds between the petals, and in connection with this by their greater sensibility, and by the lobes of the stigma being dilated. Gentiana prostrata, agreeing in every other respect with our fourth group, has as yet retained the two twisted stigma-branches, and therefore may be considered as a connecting species between the second group and the fourth, which is descended from it.

Summing up the above relations between the species of Gentiana of Germany and Switzerland, we obtain a pedigree like Fig. I I5, in which the signification of the lettering is as follows :-

(a) Hypothetical ancestral form with fully open flowers, twisted stigma-branches, diverging stamens, and honey secreted at the base of the flower in the angle between the base of the pistil and the corolla. From this ancestral form we see two branches $b$ and $c$ descend; $b$ with the nectary confined to the base of the pistil, $c$ with nectaries at the base of the coroila. From the branch $c$ has developed the sub-genus Entotricha Frolich $(d)$, containing six species:-G. campestris, germanica, amarella, obtusifolia, tenella, and nana, adapted both to Apidæ and to Lepidoptera. Of the branch $b$ an original form, $G$. lutea $\left(b^{\prime}\right)$, has been preserved, accessible to insects of all orders, but from the same branch has descended the large sub-genus Colanthe Frœlich (e), containing eleven species :--G. punctata, pannonica, purpurea, cruciata, asclepiadea, Pneumonanthe, Fiolichii, frigida, acaulis, excisa, and ciliata, all adapted to humblebees. One branch of this sub-genus $(e)$, by narrowing the corolla, perfecting the folds between the petals, dilating the stigma-branches, and thus adapting the flowers to Lepidoptera, has further developed the sub-genus Cyclostigma $(g)$, containing seven species :-G. bavarica, verna, astiva, imbricata, pumila, utriculosa, and nivalis. As a link between the ancestral sub-genus $(e)$ and the derived subgenus $G$, has been preserved $G$. prostra $a(f)$. Lippstadt HERMANN MÜLLER

\section{RECENTLY PROPOSED IMPROVEMENTS IN MUSICAL INTONATION}

THE harshness of the present system of tuning has been a source of constant complaint since it was first introduced, about a century and a half ago. But of late years several more or less practical attempts have been made to overcome this defect without interfering with the quality of our musical tones. Instruments with fixed tones, as the organ, piano, and harmonium, lead voices, and the inalterable quality of vocal tone has therefore to be constantly kept in view. The instruments exhibited in the Loan Collection of Scientific Apparatus at South Kensington are enough to show both the objects aimed at and the nature of the mechanical appliances by which it is hoped they may be more or less reached. It is difficult to give an intelligible account of them within the compass of an article, but Dr. Stone's two lectures ${ }^{1}$ and Mr. Bosanquet's more recent work ${ }^{2}$ will supply details and figures.

On examining musical tones generally, ${ }^{3}$ we are led to the conclusion that the first requisite is to have a succession of notes forming perfect Octaves, Fifths, and major Thirds, that is, making numbers of vibrations which the air executes during the same length of time in the ratios $1: 2,2: 3$, and $4: 5$ respectively. An examination of prevailing systems of modulation, has shown ${ }^{4}$ that a strict fulfilment of this condition would require $I I 7$ notes to the Octave-a mechanical impossibility on any instrument with fixed tones. Such a scheme must, however, be made the basis of subsequent work. Moreover if combinations with what is called the harmonic Seventh or $6: 7$ be admitted, then we should require very nearly to double the above number of separate notes. It follows, therefore, that we must either restrict our desires of modulation (which is not likely to happen) or be content to use more or less imperfect intervals, and the question turns upon the degree of endurable imperfection. It must be remembered that these apparently innumerable delicacies of sound present no real difficulty to the singer or violinist when he once knows the theory on which they have to be produced, for they are all generated by extremely simple intervals. The difficulty, indeed, is to avoid them, especially in part music, and to put up with alterations, apparently arbitrary and certainly neither

$x$ " Sound and Music," by Dr. W. H. Stone, in the series of Science Lectures at South Kensington, 1876 , pp. 46 . (Macmillan.)

$z$ "An Elementary Treatise on Musical Intervals and Temperament, with an Account of the Enharmonic Harmonium Exhibited in the Loan Collection of Scientific Instruments, South Kensington, $x 87^{6}$; also of an Enharmonic Organ Exhibited to the Musical Association of London, May, 1875," pp. 94, 1876 . (Macunillan.)

(1) "Sensations of Tone."

4 See my translation of Helmholtz, pp. $669-672$. 